\title{
Crude Oil Emulsion Properties and their Application to Heavy Oil Transportation
}

\author{
D. Langevin 1 , S. Poteau ${ }^{2}$, I. Hénaut ${ }^{2}$ and J.F. Argillier ${ }^{2}$ \\ 1 Laboratoire de physique des solides, université Paris-Sud, bâtiment 510, 91405 Orsay Cedex - France \\ 2 Institut français du pétrole, 1 et 4, avenue de Bois-Préau, 92852 Rueil-Malmaison Cedex - France \\ e-mail: langevin@lps.u-psud.fr - sandrine.poteau@ifp.fr - isabelle.henaut@ifp.fr - j-francois.argillier@ifp.fr
}

\begin{abstract}
Résumé - Propriétés des émulsions de pétrole brut et leurs applications au transport des bruts lourds - De nombreuses avancées ont été réalisées dans le domaine des émulsions ces dernières années. Le comportement des émulsions est en grande partie contrôlé par les propriétés des couches adsorbées qui protègent les surfaces entre l'huile et l'eau. La connaissance de la seule tension interfaciale n'est pas suffisante pour comprendre les propriétés des émulsions; la rhéologie de surface joue un rôle important dans de nombreux phénomènes dynamiques. La complexité des émulsions pétrolières vient de la composition de l'huile en termes de molécules présentant un caractère tensioactif comme les acides gras de faible masse moléculaire, les acides naphténiques et les asphaltènes. Ces molécules peuvent interagir et se réorganiser aux interfaces huile/eau. Le caractère non linéaire prononcé de la rhéologie de surface obtenu avec des couches d'asphaltènes peut expliquer les différences de comportement entre les émulsions de tensioactif et les émulsions d'asphaltène. Cet article présente une revue des propriétés des émulsions pétrolières. L'application au transport d'hydrocarbures très visqueux sous forme d'émulsion aqueuse est ensuite considérée.
\end{abstract}

\begin{abstract}
Crude Oil Emulsion Properties and their Application to Heavy Oil TransportationMany advances have been made in the field of emulsions in recent years. Emulsion behavior is largely controlled by the properties of the adsorbed layers that stabilize the oil-water surfaces. The knowledge of surface tension alone is not sufficient to understand emulsion properties, and surface rheology plays an important role in a variety of dynamic processes. The complexity of petroleum emulsions comes from the oil composition in terms of surface-active molecules contained in the crude, such as low molecular weight fatty acids, naphthenic acids and asphaltenes. These molecules can interact and reorganize at oil/water interfaces. The pronounced nonlinear behavior of surface rheology for asphaltene layers might explain differences in behavior between surfactant and asphaltene emulsions. These effects are very important in the case of heavy oils because this type of crude contains a large amount of asphaltene and surface-active compounds. This article reviews different petroleum emulsion properties and the transport of high viscosity hydrocarbon as a crude oil in water emulsion.
\end{abstract}




\section{INTRODUCTION}

Emulsions of crude oil and water can be encountered at many stages during drilling, producing, transporting and processing of crude oils and in many locations such as in hydrocarbon reservoirs, well bores, surface facilities, transportation systems and refineries. A good knowledge of petroleum emulsions is necessary for controlling and improving processes at all stages. Many studies have been carried out in the last 40 years and have led to a better understanding of these complex systems. However there are still many unsolved questions related to the peculiar behavior of these emulsions. The complexity comes mostly from the oil composition, in particular from the surface-active molecules contained in the crude. These molecules cover a large range of chemical structures, molecular weights, and HLB (Hydrophilic-Lypophilic Balance) values; they can interact between themselves and/or reorganize at the water/oil interface. To make the system even more complex these petroleum emulsions may also contain solids and gases.

In this article we will first review some of the main characteristics of crude oil emulsions, in particular adsorbed layer properties of amphiphilic molecules, properties of films between drops, emulsification, emulsion stability. We will then discuss in more detail transportation of heavy oil as aqueous emulsions. As indicated in the first article of this Oil \& Gas Science and Technology issue, one way to transport highly viscous hydrocarbon is to disperse the heavy crude oil in water as droplets stabilized by surfactants.

Oil-water emulsions are fine dispersions of oil in water $(\mathrm{O} / \mathrm{W})$ or of water in oil $(\mathrm{W} / \mathrm{O})$, with drop sizes usually in the micron range $[1,2]$. In general, emulsions are stabilized by surfactants (Fig. 1).

In some cases multiple emulsions such as water in oil in water $(\mathrm{W} / \mathrm{O} / \mathrm{W})$ or oil in water in oil $(\mathrm{O} / \mathrm{W} / \mathrm{O})$ can be found. Emulsions can be stabilized by other species, provided that they adsorb at the oil-water interface and prevent drop growth and phase separation into the original oil and water phases. After adsorption, the surfaces become viscoelastic and the surface layers provide stability to the emulsion.

Crude oils, especially the heavy oils, contain large quantities of asphaltenes (high molecular weight polar components) that act as natural emulsifiers. Other crude oil components are also surface active: resins, fatty acids such as naphthenic acids, porphyrins, wax crystals, etc, but most of the time they cannot alone produce stable emulsions [3]. However, they can associate to asphaltenes and affect emulsion stability. Resins solubilize asphaltenes in oil, and remove them from the interface, therefore lowering emulsion stability. Waxes coadsorb at the interface and enhance the stability. Naphthenic and other naturally occurring fatty acids also do not seem able to stabilize emulsions alone. However, they are probably partly responsible for the important dependence of emulsion stability upon water $\mathrm{pH}$.

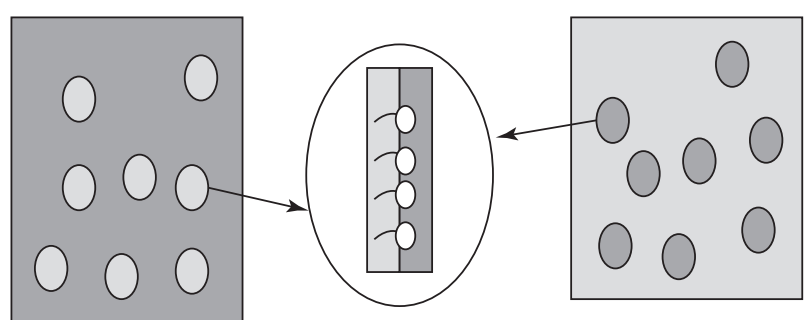

a)

b)

Figure 1

Schematic representation of emulsion structures. a) $\mathrm{O} / \mathrm{W}$ emulsion; b) W/O emulsion. Encircled: enlarged view of a surfactant monolayer sitting at the oil-water interface.

Particles such as silica, clay, iron oxides, etc. can be present in crude oils. These particles are naturally hydrophilic, but can become oil-wet (hydrophobic) due to longterm exposure to the crude in the absence of water. A decrease in the size of oil-wet particles results in an increase in W/O emulsion stability. Emulsions with particles and asphaltenes combined can be much more stable than those stabilized by asphaltenes alone, provided that enough asphaltenes are present: all the adsorption sites on the particle surface need to be saturated by asphaltenes. The resin and asphaltene content using heptane SARA (Saturated, Aromatic, Resin, Asphaltene) analysis of various heavy crude oils are given in Table 1.

TABLE 1

Resin and asphaltene content of various heavy crude oils (from [4])

\begin{tabular}{l|c|c|c|c}
\hline Crude & ${ }^{\circ}$ API & $\begin{array}{c}\text { Resin } \\
(\mathrm{wt} \%)\end{array}$ & $\begin{array}{c}\text { Asphaltene } \\
(\mathrm{wt} \%)\end{array}$ & Asph./Resin \\
\hline Canada, Atabasca & 8.3 & 14.0 & 15.0 & 1.07 \\
Venezuela, Boscan & 10.2 & 29.4 & 17.2 & 0.58 \\
Canada, Cold Lake & 10.2 & 25.0 & 13.0 & 0.52 \\
Mexico, Panucon & 11.7 & 26.0 & 12.5 & 0.48 \\
\hline
\end{tabular}

One Venezuelan oil studied at IFP has a high density ( $9^{\circ} \mathrm{API}$, density 1.0). Its composition is given in Table 2.

TABLE 2

SARA analysis and the elementary composition of oil from Venezuela. The extraction has been made by using the ASTM (American Society for Testing and Materials) 863-69 norm. (from [5])

\begin{tabular}{|c|c|c|c|c|c|c|c|}
\hline \multirow[t]{2}{*}{ (\% weight) } & \multirow[t]{2}{*}{$\begin{array}{l}\text { SARA } \\
\text { pentane }\end{array}$} & \multirow[t]{2}{*}{$\begin{array}{l}\text { SARA } \\
\text { heptane }\end{array}$} & \multicolumn{5}{|c|}{$\begin{array}{c}\text { (\% weight) } \\
\text { heptane SARA fractions }\end{array}$} \\
\hline & & & $\mathrm{C}$ & $\mathrm{H}$ & $\mathrm{N}$ & $\mathrm{O}$ & $S$ \\
\hline Asphaltenes & 17 & 14.1 & 83.8 & 7.5 & 1.3 & 1.7 & 4.8 \\
\hline Resins & 33 & 37.3 & 82.8 & 8.9 & 1.5 & 2.0 & 4.3 \\
\hline Aromatics & 37 & 37.2 & 84.3 & 10 & $<0.3$ & 1.1 & 4.0 \\
\hline Saturated & 12 & 11.4 & 86.6 & 13 & $<0.3$ & $<0.2$ & $<0.1$ \\
\hline
\end{tabular}




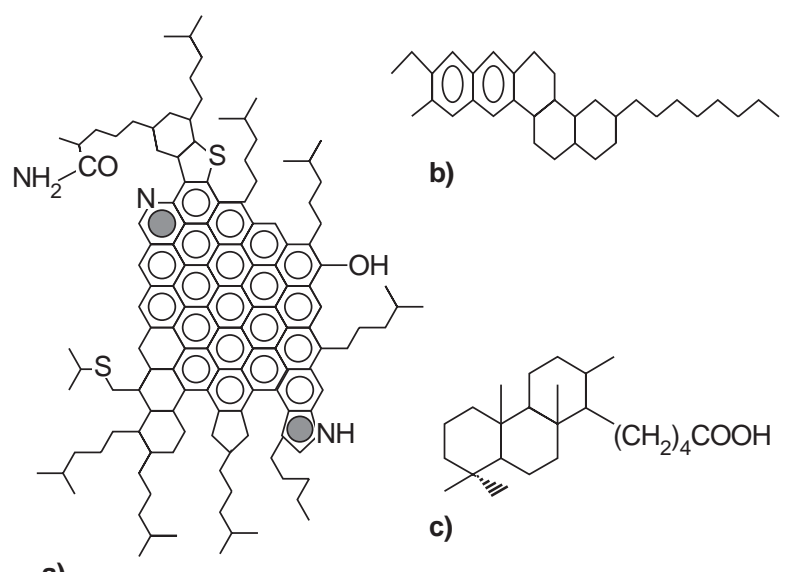

a)

Figure 2

Examples of molecular structure. a) asphaltene (adapted from proposition for 510C residue of Venezuelan crude, INTEVEP SA Tech. Rept., 1992); b) resin (Athabasca tarsand bitumen); c) naphthenic acid.

\section{ADSORBED LAYERS PROPERTIES}

When a surface active substance is added to water or oil, it spontaneously adsorbs at the surface, and decreases the surface tension $\gamma$ [6]. In the case of small surfactant molecules, a monolayer is formed, with the polar parts of the surface-active molecules in contact with water, and the hydrophobic parts in contact with oil (Fig. 1).

Surfactant adsorption is generally very fast, but for larger molecules, such as asphaltenes, the adsorption process is longer and adsorption is generally irreversible. In certain circumstances, asphaltenes can adsorb in the form of aggregates, the surface layers become thick, and a solid-like "skin" is formed (Fig. 3).
Asphaltenes are polycyclic molecules that are disc shaped, and have a tendency to form stacked aggregates. They are molecularly dispersed in aromatic solvents such as toluene, and precipitate in alkanes: their precipitation limit is around $60 \%$ heptane (Venezuelan oil) in mixtures of heptane and toluene. The corresponding emulsions have a stability which is maximum just before precipitation, because there is a maximum amount of adsorbed asphaltenes [8,9]. Above the precipitation boundary, the asphaltenes precipitate and fewer asphaltenes are available to cover the interface. Asphaltenes contain also polar groups (ester, ether, carbonyl) and acidic and basic groups (carboxylic and pyridine functional groups) that can be ionised in a certain range of $\mathrm{pH}$. The stability of emulsions formed with our Venezuelan asphaltene solutions in toluene is minimum at $\mathrm{pH} 8$ [10]. Similar results were
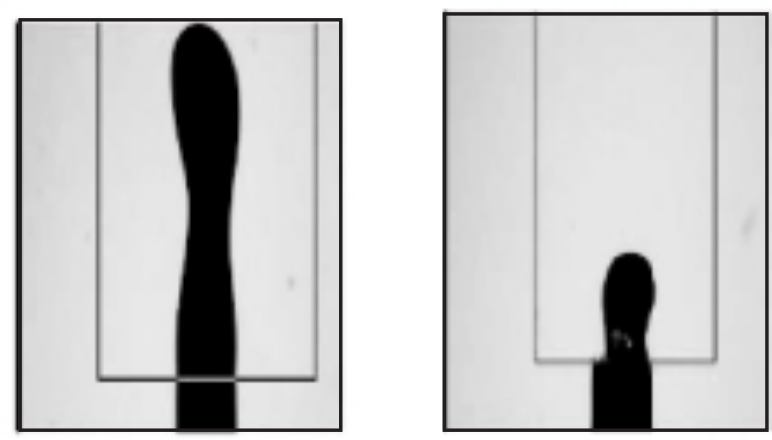

a)

Figure $3 \mathrm{a}$

Oil drops containing asphaltenes held by a capillary tube (bottom, by which liquid can be injected or sucked off) immersed in water; the irregular shapes are due to the presence of "skins" at the oil/water interface; left: expanded drop, right: shrunken drop. From [5].
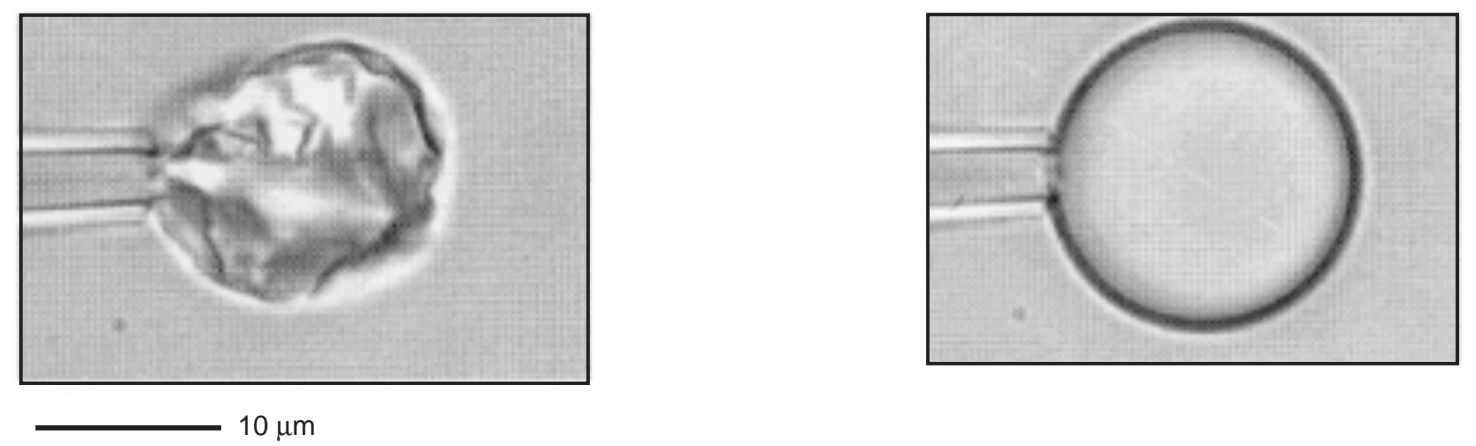

b)

Figure $3 b$

Water drops surrounded by $0.1 \%$ Athabasca bitumen in heptol, held by a micropipette. Left: shrinked drop, right: normal drop. From [7]. 
found with emulsions made with another Venezuelan crude oil (13.2 $\left.2^{\circ} \mathrm{API}\right)$ diluted with toluene (50:50) [11]. This is accompanied by a maximum of the interfacial tension, suggesting that at the intermediate $\mathrm{pH}$, the asphaltenes are less surface active. Note that it was observed that the "skins" were no longer present above $\mathrm{pH} 8$. Resin films are on the contrary stronger at basic $\mathrm{pH}$, suggesting that they have a weakly acidic nature. The $\mathrm{pH}$ sensitivity is probably also affected by the naphthenic acids, but little information can be found in the literature.

Resins lead generally to less stable emulsions. However, if asphaltenes are partly precipitated, the addition of resins can resolubilize them and produce an increase in stability, but if the resin concentration is too high, the stability is not improved [12].

Emulsions stabilized with particles are called "pickering emulsions" [13]. It is generally considered that since the size of stable emulsion drops is generally $10 \mu \mathrm{m}$ or less, the particles contributing to emulsion stabilization should not be more than $1 \mu \mathrm{m}$ in size. Many authors showed an increase in emulsion stability with a decrease in particle size. Adsorption of solid particles is also irreversible if the contact angle is close to $90^{\circ}$ (Fig. 4). At particle concentrations above those required for monolayer coverage, coalescence rates decrease significantly. Particles also can form multilayers, and this is considered as a guarantee of good emulsion stability.

Hydrophilic particles stabilize O/W emulsions if they are small and their surfaces are not modified, but they stabilize W/O emulsions if dried and added to an asphaltenecontaining oleic phase [14]. Montmorillonite, kaolin and $\mathrm{Fe}_{2} \mathrm{O}_{3}$ do stabilize W/O emulsions when predried. Montmorillonite stabilizes emulsions more effectively than kaolin because it can swell, increasing its interaction with asphaltenes by exposing interlamellar adsorption sites. $\mathrm{Ca}(\mathrm{OH})_{2}$ particles stabilize W/O emulsions even when not predried. $\mathrm{Ca}(\mathrm{OH})_{2}$ is basic and can interact with the asphaltenes acidic groups. Comparisons between crude and model oil emulsion systems indicate that resin and asphaltene fractions are responsible for the effectiveness of solid particles in crude oil emulsion stabilization. The extent of asphaltene aggregation is the dominant factor for controlling solid stabilization effectiveness: asphaltenes are most effective at modifying particle surfaces and stabilizing emulsions close to their precipitation limit.

The case of silica particles has been extensively studied, in view of the problem of separation of sand and bitumen in Canada. It has been shown that sand can be detached from bitumen if the $\mathrm{pH}$ of the water used in the extraction process is above 8 . The interactions between a bitumen model surface and a silica sphere have been directly measured by AFM (Atomic Force Microscopy) [15]. The adhesion energy decreases when temperature and $\mathrm{pH}$ increase, and becomes very small at a $\mathrm{pH}$ above 8 . The long range repulsive force increases with increasing temperature and $\mathrm{pH}$. The $\mathrm{pH}$ should not be increased too much, because the repulsive force decreases significantly with the amount of added ions. In particular, divalent ions such as calcium produce a very important increase in adhesion, and should be avoided whenever possible. The industrial scale bitumen extraction operates at a $\mathrm{pH}$ around 8.5 as a compromise. This result is in line with the minimum of the stability of $\mathrm{W} / \mathrm{O}$ emulsions containing only asphaltenes at around $\mathrm{pH} 8$.

In stable emulsions, where the adsorbed surface layers are dense and both elastic and viscous, the interfacial tension does not play a major role. The "surface rheology" is especially important. Indeed, very rigid but brittle surface layers can rupture. Figure 5 shows that this happens for particle layers.

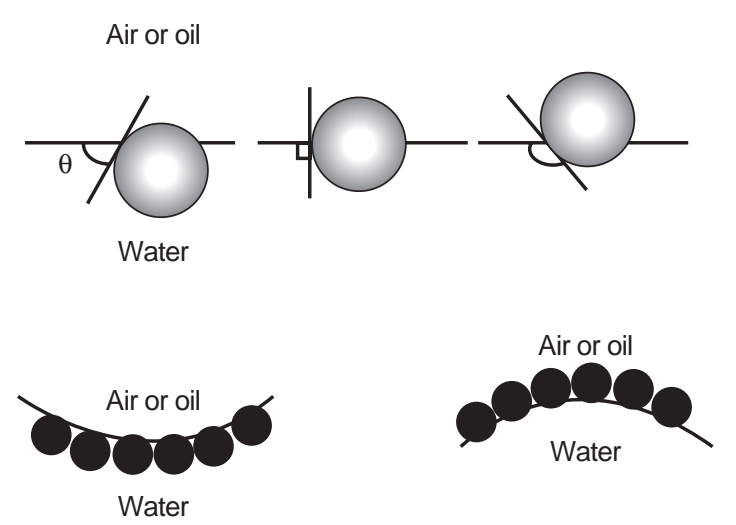

Figure 4

Upper: position of a small spherical particle at a planar interface for a contact angle $\mathrm{q}$ (measured through the aqueous phase) less than $90^{\circ}$ (left), equal to $90^{\circ}$ (center) and greater than $90^{\circ}$ (right). Lower: corresponding position of the particles at an emulsion drop surface. For $\mathrm{q}<90^{\circ}$, O/W emulsions may form (left), for $\mathrm{q}>90^{\circ}$, W/O emulsions may form (right).

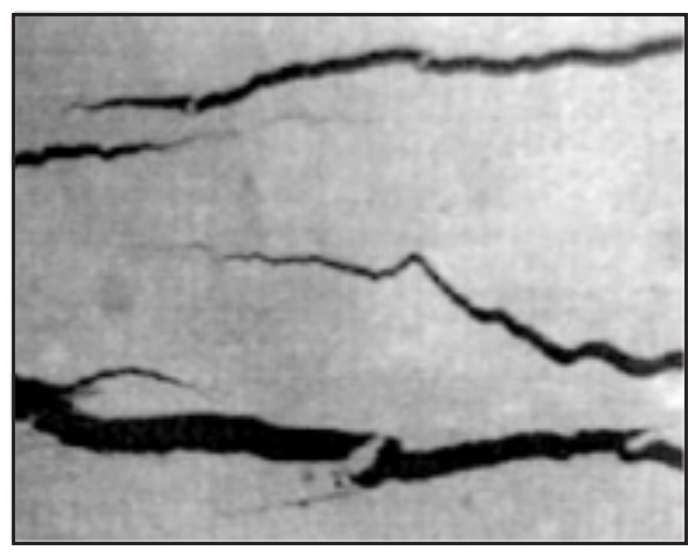

Figure 5

Microscopy images of the surface of a spread monolayer of ferrofluid particles after expansion. From [16]. 
Asphaltene layers appear more viscoelastic, although little is known about their response to large shear or compression.

\section{PROPERTIES OF FILMS BETWEEN DROPS}

Transient films can be formed during collisions between drops. If repulsive forces between the drops are not too strong and if adhesion energies large enough, adhesion can be promoted (Fig. 6). This is the phenomenon called "flocculation".

If the film ruptures, the drops fuse, this is the "coalescence" process. Emulsion stability is therefore closely related to surface forces and film stability.

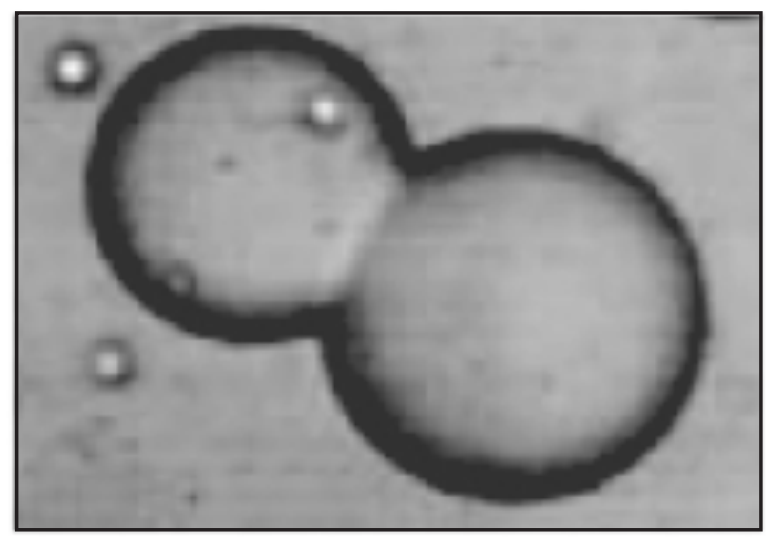

Figure 6

Adhesion between two emulsion droplets. From [2].

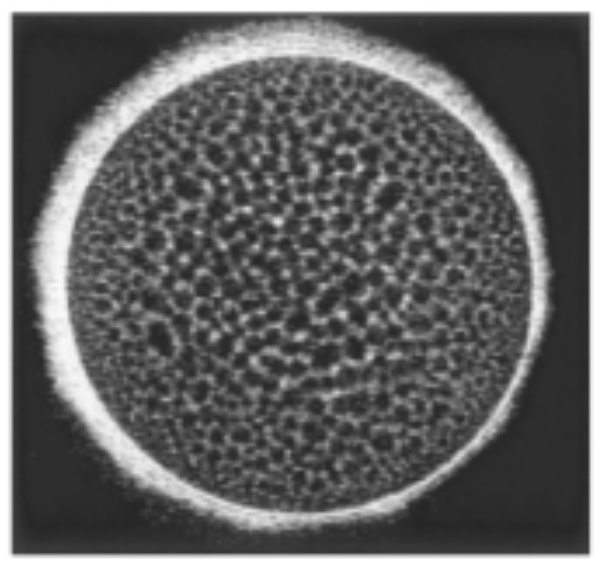

Figure 7

Heptane diluted bitumen films. Over time (after 2 h), the number of asphaltene aggregates increases until any newly formed film becomes completely clogged preventing it from draining. From [17].
Film thinning and rupture can occur in many different ways. In the case of crude oil emulsions, and when asphaltenes form "skins" at the oil-water interface, thinning of emulsion films is very complex: films are thick and irregular, large aggregates are trapped in the film and stop the thinning process (Fig. 7).

This could explain why emulsions are very stable when large amounts of asphaltenes are present at the drop surface.

Particles can also contribute to stability when large enough amounts of asphaltenes are adsorbed at their surface: the sticky character of the adsorbed layer is reinforced, the thickness is larger, and the layer is more difficult to break [18]. When the particles are more soluble in either oil or water, they will not adsorb at the surface of the drops. If they remain in the continuous phase, they will not enter the films, and act as film stabilizers. If they are more soluble in the disperse phase (contact angle larger than $90^{\circ}$ ), they can either spread at the film surface (if they are liquid) or bridge the two surfaces of the film (Fig. 8). These two scenarios are classical in antifoam action and lead to a quick rupture of the films [19].
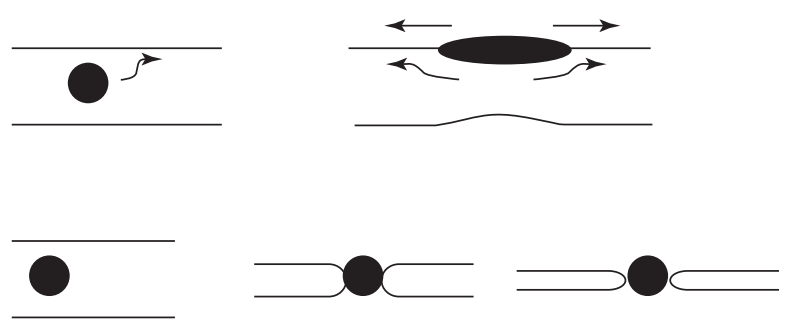

Figure 8

Schematic representation of two mechanisms for demulsification by a liquid drop. Above: film thinning due to drop spreading, below: film rupture due to bridging and dewetting.

\section{EMULSIFICATION}

About 100 years ago, Bancroft proposed that when oil, water and surfactant are mixed, the continuous phase of the emulsion that forms is the phase where the surfactant is more soluble.

When particles are used to stabilize emulsions, the Bancroft rule translates into a condition for the contact angle $\theta$ between the particle and the oil-water interface. If $\theta>90^{\circ}$, the emulsion formed is $\mathrm{W} / \mathrm{O}$, if $\theta<90^{\circ}, \mathrm{O} / \mathrm{W}$; the contact angle should not be too far from $90^{\circ}$, otherwise the energy required to remove particles from the interface is small, and the emulsions are not very stable [11]. For particles with $\theta \sim 90^{\circ}$, both $\mathrm{O} / \mathrm{W}$ and $\mathrm{W} / \mathrm{O}$ emulsions can be made stable for long periods. Inversion occurs without hysteresis, by increasing or decreasing water volume fraction. This is in 
contrast to surfactant systems, where emulsions either do not invert (and form gel emulsions instead) or invert with a considerable hysteresis (as much as 0.3 in volume fraction). In addition, pickering emulsions are most stable near inversion, unlike surfactant emulsions, which become notoriously unstable. The reason for these features is still unclear.

There is a large variety of emulsification methods: simple shaking, mixing with rotor-stator systems, liquid injection through porous membranes, or high pressure devices (homogenizers, liquid jets), etc. [20]. When the emulsion is formed, the interfaces are stretched rapidly and ruptured in different flow conditions according to the method used: laminar with low shear mixers, extensional with jets and porous membranes, turbulent with mixers having toothed rotors and high pressure homogenizers.

In laminar flow conditions, the stress exerted on a drop by the flow is $\eta G$, where $\eta^{\prime}$ is the continuous phase viscosity and $G$ is the velocity gradient; this stress is counteracted by the Laplace pressure $2 \gamma / R$, where $R$ is the drop radius. The ratio of the two stresses is (half) the "capillary" number:

$$
C a=\eta G R / \gamma
$$

If $\mathrm{Ca}$ is larger than a critical value $\mathrm{Ca} a_{c r}$, the drop splits into two smaller drops (Taylor problem). $C a_{c r}$ depends on the type of flow and on the viscosity ratio $\lambda=\eta_{i} / \eta, \eta_{i}$ being the dispersed phase viscosity. The variation with $\lambda$ predicted for $C a_{c r}$ is shown on Figure 9 in the case of laminar flow.

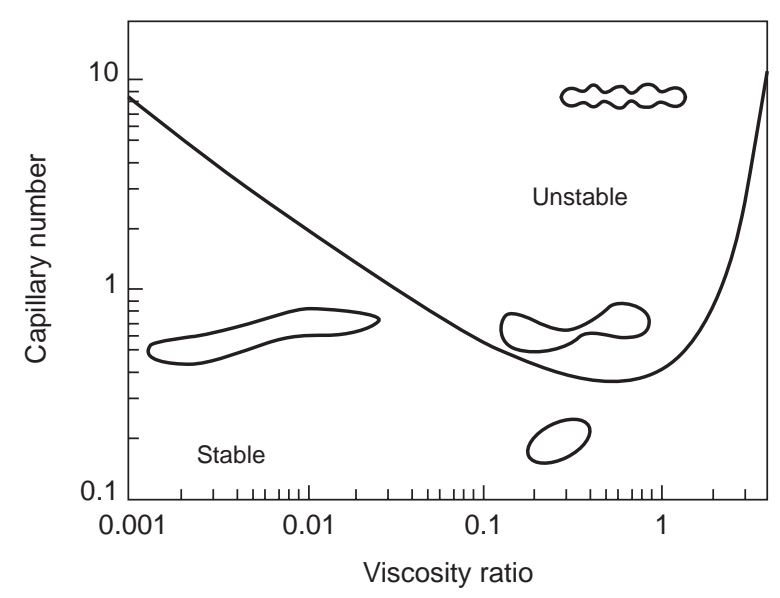

Figure 9

Critical capillary number (solid line) for drop rupture in a shear flow as a function of the viscosity ratio.

When surfactant is present, $C a_{c r}$ is somewhat larger. The difference is attributed to the supplementary energy needed to counteract surface tension gradients. Figure 9 shows that there is a divergence of $C a_{c r}$ if $\eta_{i} / \eta>4$. The main reason for this is that the droplet cannot deform as fast as dictated by the shear flow; after deforming to some extent, it starts rotating at a frequency $G / 2$. In elongational flow, no rotation is induced, and even viscous drops can be deformed and broken up. In the range of viscosity ratio of Figure 9, in the case of plane-hyperbolic flow, $\mathrm{Ca}_{c r} \sim 0.3$ and is almost constant. It is therefore easier to emulsify viscous liquids by using elongational flows.

When crude oil emulsions are formed, the skins have not had time to form, and the above results should apply. It can be seen in particular that in view of the large crude viscosity, W/O emulsions will preferentially be formed under applied shear.

If membranes are used, the flow is elongational and very effective: small drop sizes are obtained at much lower energy density than with other devices. The emulsion that forms is that for which the dispersed phase wets the membrane material (Fig. 10).

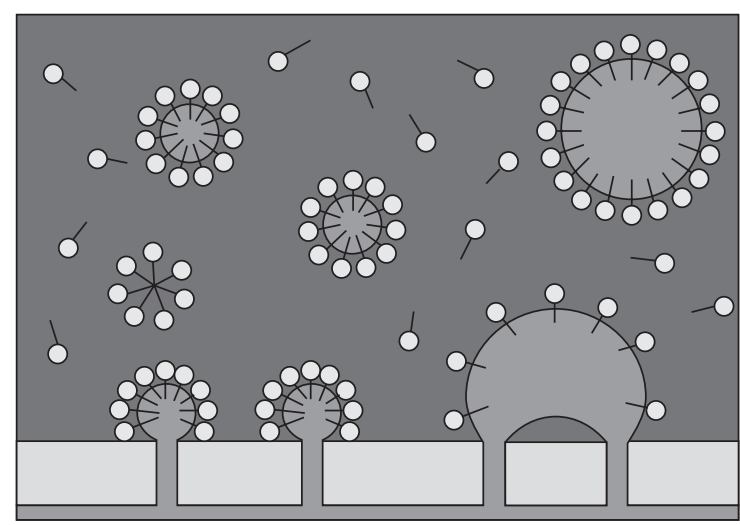

Figure 10

Schematic representation of the membrane emulsification process; left: rapidly adsorbing emulsifier; right: slowly adsorbing emulsifier. Adapted from [21].

This could occur when filtering the sand particles if oil and water are phase separated. The emulsion drop size is of the order of the pore size or larger.

Turbulent flows occur in mixers with toothed rotor-stator systems, toothed discs dispersing machines and highpressure homogenizers. The maximum droplet radius in the case of stirrers (Ultra Turrax ${ }^{\circledR}$ ) and ultrasonic transducers is: $R \sim \varepsilon^{-2 / 5} \gamma^{3 / 5}$, where $\varepsilon$ is the power density (amount of energy dissipated per unit time and unit volume). In the case of homogenizers, the power density depends on the pressure and when accounting for this dependence, one finds $R \sim \varepsilon^{-3 / 5}$. Both relations are verified experimentally. For the same energy density, the size $R$ decreases by several orders of magnitude between stirrers, ultrasonic transducers and homogenizers, simply because the speed at which energy is dissipated increases considerably (the volume of 
the dispersing zones and the corresponding residence time decrease).

Drops leaving the dispersing zone are not fully covered if a slowly adsorbing emulsifier is used. Part of the drops therefore coalesces in the regions following this zone and the emulsion may break during production. The residence time in the dispersing zone is therefore a very important parameter.

For a given supplied energy, the drop size decreases in the order: rotor-stator (laminar) > rotor-stator (turbulent) $>$ high pressure homogenizer $>$ membrane.

\section{EMULSION STABILITY}

In the following, we will recall briefly the different mechanisms leading to emulsion destabilization.

\subsection{Ostwald Ripening}

Ostwald ripening is the drop growth process occurring when the dispersed phase has a finite solubility into the continuous phase and can migrate between drops of different sizes. Lifshitz and Slyozov predicted the corresponding time variation of drop radius:

$$
R(t)=\left(\frac{8 \gamma D c_{e q} v_{m}^{2}}{9 k T}\right)^{1 / 3} t^{1 / 3}
$$

where $c_{e q}$ is the equilibrium concentration of the molecules of the dispersed phase in the continuous one, $D$ their diffusion coefficient there, $v_{m}$ their molecular volume. The growth is faster at large drop volume fractions making exchanges between drops easier. In the case of heavy crude oils, the solubilities of oil in water or of water in oil are low, and this process is likely to be very slow. No studies have been reported to our knowledge so far.

\subsection{Sedimentation or Creaming}

Emulsions with small drops $(R<1 \mu \mathrm{m})$ are insensitive to sedimentation or creaming, Brownian motion dominating the effect of gravity; but when drop sizes are larger than a few microns, they sediment or rise ("cream"). For dilute dispersions, the sedimentation velocity of a drop of radius $R$ and density $\rho_{i}$ in a fluid of density $\rho$ and viscosity $\eta$ is (if $\left.\rho_{i}>\rho\right)$ :

$$
V=\frac{2 R^{2}\left(\rho_{i}-\rho\right) g}{9 \eta}
$$

where $g$ is the acceleration of gravity. If $\rho>\rho_{i}$, the drop rises, and the velocity is given by the same expression, provided the sign of the density difference is changed. The drop volume fraction $\phi$ increases with time, either in the bottom or at the top of the emulsion sample, where drops concentrate locally. When $\phi \sim 60 \%$ in this region, drops are no longer spherical, they distort into polyhedra, the flattened regions between them being liquid films as in foams (these are the so called "cream emulsions") (Fig. 11).

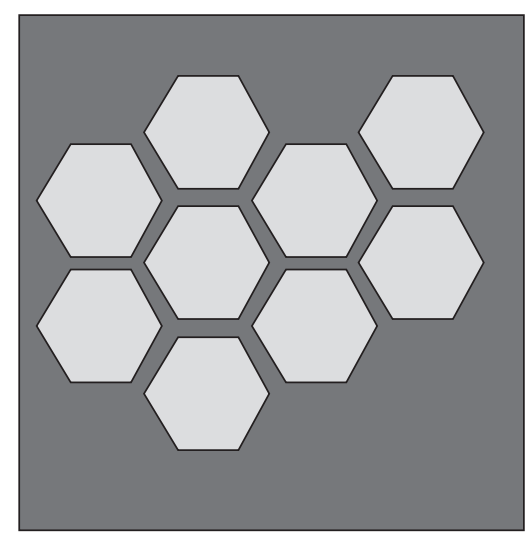

Figure 11

Emulsions with high internal volume fraction.

The drop volume fraction continues to increase, although much more slowly than predicted by Equation (3). The liquid then flows through the interstitial spaces between drops. With time, the films separating the drops thin and eventually break. This process is accelerated when flocculation occurs, simply because flocs have larger sizes.

\subsection{Coalescence (Spontaneous)}

The efficiency of the emulsification is closely related to the adsorption kinetics of surface-active molecules. For surfactant concentrations of the order of one weight $\%$, the adsorption times are much shorter than the characteristic times for emulsification, and surfactant adsorption kinetics do not therefore influence emulsification. In the presence of asphaltenes, one would expect that the emulsions will be much more stable when the skins are present. However, this type of film was observed after equilibration times much longer than the times of emulsion formation. Indeed aged crude oil emulsions were found more difficult to demulsify. In our opinion, spontaneous coalescence can only occur before the formation of skins, and in any case, when small amounts of asphaltenes are adsorbed.

\subsection{Coalescence Under Stress}

Emulsions in which drops are covered by dense adsorbed layers do not coalesce spontaneously. Coalescence can be however produced by applying either compression or shear. In the first case, osmotic compression or centrifugation can 
be used. Theory predicts that coalescence rate increases with increasing drop size, as observed experimentally. Surfactant emulsions undergoing coalescence then become very polydisperse [2]. Pickering emulsions are again unusual in this respect: Leal-Calderon and coworkers showed that coalescence stops when the drop coverage corresponds to full coverage, and that the drop size distribution is quite narrow. This is because, adsorption being irreversible, drop coverage increases during the growth process, and the coalescence rate decreases with drop size (even millimeter-sized drops are very stable against coalescence) [22].

Surfactant stabilized emulsions are generally stable against shear, even when the drop volume fraction is large. Concentrated protein emulsions are stable upon compression, but can collapse under the application of small shears, ultimately because of the fracture of the surface layers [23]. It is often stated and observed that protein-surfactant mixtures give more stable emulsions than proteins alone. Surfactants make the rigid protein layer more flexible and mobile, and the idea is that the layer is then better able to respond to applied stresses without rupturing. These ideas can probably be extended to crude oil emulsions.

\section{APPLICATION TO HEAVY OIL TRANSPORTATION}

When mixing water and crude oil, a water in oil emulsion most often is created because the surface active amphiphilic molecules in the crude are mostly oil soluble due to their low polarity (depending on $\mathrm{pH}$ for fatty acids) and molecular weight [24]. As the viscosity of an emulsion is always larger than the viscosity of the continuous phase, it is obvious that for transporting highly viscous heavy oil it is necessary to make an emulsion with water as the continuous phase [2527]. To make such an aqueous emulsion one has to fight the natural tendency to form a water in oil emulsion. There are basically two ways for making a heavy oil in water emulsion [28]: the first one is to add a high HLB (hydrophilic/ lipophilic balance) natural or synthetic surfactant. In general nonionic emulsifiers are a good choice because they are not affected by the salinity of the produced water, they are relatively cheap, and they do not produce any undesirable organic residue that can affect the oil properties [29-31]. The second way is to "activate" the natural surfactants which are part of heavy crude oil composition: one can make these surfactants more hydrophilic by ionizing the acid functional groups carried by the fatty acids and asphaltenes (from low molecular weight species to carboxylic functions carried by asphaltenes) with a strong base like soda. Addition of strong bases is a well know process in enhanced oil recovery by decreasing interfacial tension to very low values [32-38]. The presence of natural saponifiable acids in some crudes may eliminate the need for expensive commercial surfactants. Emulsions suitable for pipeline transport, containing as much as $75 \%$ crude, have been made with some crudes mixed with alcaline water.

As shown in Figure 12, viscosity reduction can be very important, more than 2 orders of magnitude [39, 40]. For obvious economical reasons oil operators seek to transport as much oil as possible and as little water as possible. To keep the viscosity of aqueous heavy oil emulsion below the required value of specification of pipelines transport (typically around $400 \mathrm{cP}$ at ambient temperature), a maximum of 70 to $75 \%$ in volume of dispersed bitumen phase is acceptable. Above $70 \%$, the viscosity becomes too high [39-42].

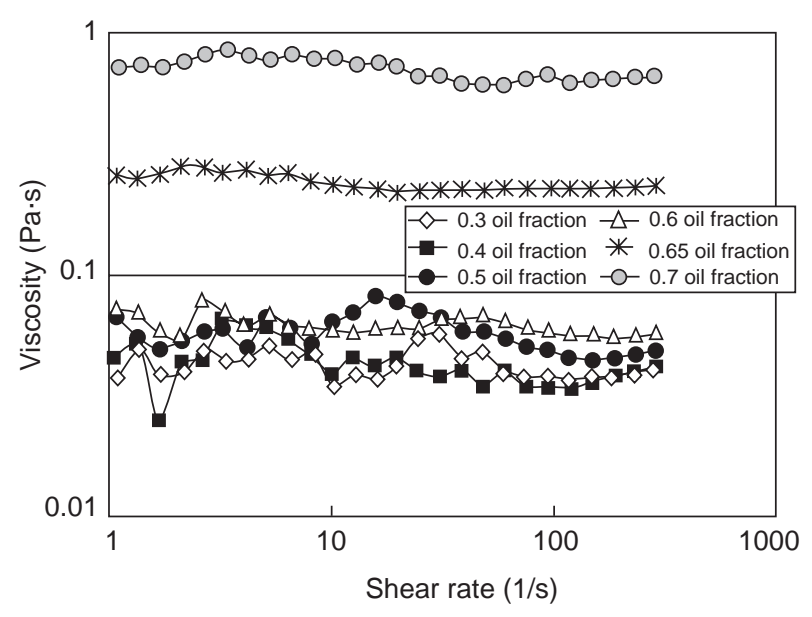

Figure 12

Viscosity of oil/water emulsions at different shear rates.

Formation of oil-in-water emulsions to reduce the viscosity of heavy crude oils and bitumens has been under investigation to provide an alternative to the use of diluents or heat to reduce viscosity in pipelines [41-48]. Moreover, emulsion viscosity is far less sensitive to temperature than that of heavy oil [39, 40]. Simon et al. [49] have also shown that restarting a pipeline after an emergency shutdown and reemulsification of oil does not pose major problems.

The major application of heavy oil aqueous emulsion is the ORIMULSION ${ }^{\circledR}$ process developed by PDV (Petroléos de Venezuela) in the eighties. ORIMULSION ${ }^{\circledR}$ is an aqueous bitumen emulsion, made of $30 \%$ water and $70 \%$ natural extra heavy oil, which is directly used as a feedstock for power generation in thermoelectrical plants. Feasibility of this technology has been clearly demonstrated by the large-scale development of the commercial product. A good review of this process can be found in [50].

Besides ORIMULSION ${ }^{\circledR}$, the technical viability of pipeline transportation of heavy crude oil as oil-in-water emulsions that contain high fractions of oil has been 
demonstrated in an Indonesian pipeline in 1963 and in a 13mile long, 8-in. diameter pipeline in California [43].

As we have seen in the previous parts, stability of the emulsion depends on many parameters. Let us just cite some of the main ones: oil composition in terms of surface active molecules [25, 28], salinity and $\mathrm{pH}$ of the water [33, 43], oil/water volume ratio [26], droplets size and polydispersity $[25,26]$, temperature $[26,29]$, surfactant type and concentration $[26,42]$, mixing energy $[25,26]$. A large number of studies, mostly experimental in nature, have been carried out on oil-water emulsions [25, 45]. However, the results of these studies are not always consistent. The reason is that the behavior of emulsions is complex and as mentioned above, depends on many factors $[32,40]$. It is beyond the scope of this article to review in details the influence of the different parameters. A good review using formulation-composition maps of heavy hydrocarbon emulsions has been proposed by Salager et al. [50].

Obviously rheology of these emulsions is an important issue for transportation. Some of the main parameters that will control emulsion rheology are the oil dispersed volume fraction and droplet size distribution [51,52]. Depending on the conditions, heavy oil aqueous emulsions can present either a Newtonian or a shear thinning rheological behavior $[51,53]$. The droplet size distribution is a function of different parameters which are not independent with one another, in particular of surfactant type and concentration [40-42], $\mathrm{pH}$ of the aqueous phase [43], surface tension [25, 32], mixing energy [25, 42], ionic strength [25, 42], temperature $[29,40]$, chemistry of the natural surfactant of the crude oil [31,33], pressure [52]. Besides viscosity, the formation of a lubricating layer around the pipewall resulting from migration of droplets away from the pipewall due to the hydrodynamic conditions [50] has been reported. This could explain the pressure drop during pipeline transportation, which is lower than that expected from rheological measurements $[46,54]$. Some further investigations are needed on this subject.

ORIMULSION $^{\circledR}$ is directly used as a feedstock for power generation in thermoelectrical plants. Another strategy for crude oil in water emulsions could be to separate the crude and the water after transportation, at the refinery entry, and subsequently to upgrade the crude [55]. In this case, from a practical point of view, emulsion properties required for a given dispersed oil volume fraction are the following:

- viscosity as low as possible;

- sufficient stability in dynamic conditions during transportation and in static conditions in case of shutdown;

- conditions which allow performant oil and water separation after transportation.

An option for transporting heavy oil is to use $\mathrm{NH}_{4} \mathrm{OH}$ as a base to saponify fatty acids so as to form the oil in water emulsion and to break the emulsion after transportation by evaporating the ammonia when heating the emulsion.
Ammonia can then be recovered and recycled [35]. Breaking these emulsions is a challenge for different reasons:

- The density of heavy oil is very close to the density of water. Without additional treatment, classical physical techniques using density difference (gravity separators, centrifuge systems, etc.) are poorly efficient for separating the heavy crude and the water. Raising the temperature of the emulsion, adding a low-density diluent or adding salt can increase the density difference and enhance the emulsion separation.

- Heavy oils contain a large amount of asphaltene or more generally of amphiphilic molecules. As mentioned these molecules interact and reorganize at the interface forming strong films that give very stable emulsions.

- Inversion of the emulsion is difficult to avoid and is detrimental, leading to fine water droplets which are afterwards very difficult to separate, due to the high viscosity of the crude and the large amount of surface active molecules.

Procedures for demulsification of heavy crude oil emulsion can combine different techniques: raising the temperature, addition of a well chosen demulsifier system, addition of solvents, addition of salts, $\mathrm{pH}$ modification, application of an electrical field, stripping with gas, etc.

\section{CONCLUSION}

Emulsion behavior is largely controlled by the properties of the adsorbed layers that protect the oil-water surfaces. The knowledge of surface tension alone is not sufficient to understand emulsion properties, and the surface viscoelasticity plays an important role in a variety of dynamic processes. This is perhaps more true for asphaltene emulsions, although in this case, the pronounced nonlinear behavior makes the phenomena richer and more difficult to interpret. Among the dynamic processes, emulsion film rupture is certainly the least well understood, and is visibly very different when asphaltenes are present. Unexpectedly, protein emulsions behave in a manner very similar to crude oil emulsions containing asphaltenes. Dispersing heavy oil or bitumen in water is a very efficient way to reduce the viscosity of the fluid by more than 2 orders of magnitude. It can be achieved by addition of hydrophilic surfactant or activation of the natural surfactants contained in the crude oil with a strong base. Stability and rheology of these emulsions depend on various parameters. The whole subject has been considerably clarified in the recent years but some aspects deserve further investigations, in particular heavy oil emulsion rheology and flow properties and interfacial properties of asphaltene/fatty acids mixed systems. In this way, a better understanding of the relationships between microscopic interactions and macroscopic emulsion properties will be achieved. 


\section{REFERENCES}

1 Sjöblom, J. (2001) Encyclopedic Handbook of Emulsion Technology, Marcel Dekker, New York.

2 Bibette, J., Leal-Calderon, F., Schmitt, V. and Poulin, P. (2002) Introduction, in: Emulsion science - Basic principles, Springer.

3 Lee, R.F. (1999) Agents which Promote and Stabilize Waterin-Oil Emulsions. Spill Science and Technology Bulletin, 5, 117-126.

4 Asphaltene Deposition and its Control (2004).

http://tigger.uic.edu/ mansoori/Asphaltene.Deposition.and. Its.Control_html

5 Jeribi, M., Almir-Assad, B., Langevin, D., Henaut, I. and Argillier, J.F. (2002) Adsorption Kinetics of Asphaltenes at Liquid Interfaces. Journal of Colloid and Interface Science, 256, 268-272.

6 Adamson, A.W. (1976) Physical Chemistry of Surfaces. Wiley, New York.

7 Yeung, A., Dabros, T., Masliyah, J. and Czarnecki, J. (2000) Micropipette: a New Technique in Emulsion Research. Colloids and Surfaces A-Physicochemical and Engineering Aspects, 174, 169-181.

8 Mclean, J.D. and Kilpatrick, P.K. (1997) Effects of Asphaltene Aggregation in Model Heptane-Toluene Mixtures on Stability of Water-in-Oil Emulsions. Journal of Colloid and Interface Science, 196, 23-34.

9 Mclean, J.D. and Kilpatrick, P.K. (1997) Effects of Asphaltene Solvency on Stability of Water-in-Crude-Oil Emulsions. Journal of Colloid and Interface Science, 189, 242-253.

10 Poteau, S. (2004) Heavy Oil Transportation as Aqueous Emulsion. PhD Thesis Report, Paris 6 university.

11 Strassner, J.E. (1968) Effect of pH on Interfacial Films and Stability of Crude Oil-Water Emulsions. SPE 1939.

12 Spiecker, P.M., Gawrys, K.L., Trail, C.B. and Kilpatrick, P.K. (2003) Effects of Petroleum Resins on Asphaltene Aggregation and Water-in-Oil Emulsion Formation. Colloids and Surfaces A-Physicochemical and Engineering Aspects, 220, 9-27.

13 Binks, B.P. (2002) Particles as Surfactants - Similarities and Differences. Current Opinion in Colloid \& Interface Science, 7, 21-41.

14 Sullivan, A.P. and Kilpatrick, P.K. (2002) The Effects of Inorganic Solid Particles on Water and Crude Oil Emulsion Stability. Industrial \& Engineering Chemistry Research, 41, 3389-3404.

15 Liu, J.J., Xu, Z.H. and Masliyah, J. (2003) Studies on Bitumen-Silica Interaction in Aqueous Solutions by Atomic Force Microscopy. Langmuir, 19, 3911-3920.

16 Lefebure, S., Menager, C., Cabuil, V., Assenheimer, M., Gallet, F. and Flament, C. (1998) Langmuir Monolayers of Monodispersed Magnetic Nanoparticles Coated with a Surfactant. Journal of Physical Chemistry B, 102, 27332738 .

17 Khristov, K., Taylor, S.D., Czarnecki, J. and Masliyah, J. (2000) Thin Liquid Film Technique - Application to WaterOil-Water Bitumen Emulsion Films. Colloids and Surfaces A-Physicochemical and Engineering Aspects, 174, 183-196.

18 Gafonova, O.V. and Yarranton, H.W. (2001) The Stabilization of Water-in-Hydrocarbon Emulsions by Asphaltenes and Resins. Journal of Colloid and Interface Science, 241, 469-478.
19 Garrett, P.R. (1993) Defoaming, Theory and Industrial Applications, Surfactant Scicence Serries 45, M.Dekker, New-York.

20 Walstra, P. (1993) Principles of Emulsion Formation. Chemical Engineering Science, 48, 333-349.

21 Schroder, V., Behrend, O. and Schubert, H. (1998) Effect of Dynamic Interfacial Tension on the Emulsification Process using Microporous, Ceramic Membranes. Journal of Colloid and Interface Science, 202, 334-340.

22 Arditty, S., Whitby, C.P., Binks, B.P., Schmitt, V., and LealCalderon, F. (2003) Some General Features of Limited Coalescence in Solid-Stabilized Emulsions. European Physical Journal, 11, 273-281.

23 van Aken, G.A. and Zoet, F.D. (2000) Coalescence in Highly Concentrated Coarse Emulsions. Langmuir, 16, 7131-7138.

24 Acevedo, S., Escobar, G., Gutierrez, L.B., Rivas, H. and Gutierrez, X. (1993) Interfacial Rheological Studies of ExtraHeavy Crude Oils and Asphaltenes - Role of the Dispersion Effect of Resins in the Adsorption of Asphaltenes at the Interface of Water-In-Crude Oil-Emulsions. Colloids and Surfaces A-Physicochemical and Engineering Aspects, 71, 65-71.

25 Ahmed, N.S., Nassar, A.M., Zaki, N.N. and Gharieb, K.H (1999) Stability and Rheology of Heavy Crude Oil-in-Water Emulsion Stabilized by an Anionic-Nonionic Surfactant Mixture. Petroleum Science and Technology, 17, 553-576.

26 Sun, R. and Shook, C.A. (1996) Inversion of Heavy Crude Oil-in-Brine Emulsions. Journal of Petroleum Science and Engineering, 14, 169-182.

27 Hénaut, I., Barré, L., Argillier, J.F., Brucy, F. and Bouchard, R. (2001) Rheological and Structural Properties of Heavy Crude Oils in Relation with their Asphaltenes Content. SPE 65020 .

28 Elgibaly, A.A.M., Nashawi, I.S. and Tantawy, M.A. (1997) Rheological Characterization of Kuwaiti Oil-Lakes Oils and their Emulsions. SPE 37259, 493-508.

29 Sharma, K., Saxena, V.K., Kumar, A., Ghildiyal, H.C., Anurada, A., Sharma, N.D., Sharma, B.K., and Dinesh, R.S. (1998) Pipeline Transportation of Heavy Viscous Crude oil as Water Continuous Emulsion in North Cambay Basin (India). SPE 39537.

30 Gillies, R.G., Sun, R., and Shook, C.A. (2000) Laboratory Investigation of Inversion of Heavy Oil Emulsions. Canadian Journal of Chemical Engineering, 78, 757-763.

31 Al-Sabagh, A.M., Zaki, N.N., and Badawi, A.F.M. (1997) Effect of Binary Surfactant Mixtures on the Stability of Asphalt Emulsions. Journal of Chemical Technology and Biotechnology, 69, 350-356.

32 Plegue, T.H., Frank, S.G., Fruman, D.H., and Zakin J.L. (1989) Studies of Water-Continuous Emulsions of Heavy Crude Oils Prepared by Alkali Treatment. SPE 18516.

33 Plegue, T.H., Frank, S., Fruman, D., and Zakin, J.L. (1986) Viscosity and Colloidal Properties of Concentrated Crude Oil in Water Emulsions. Journal of Colloid and Interface Science, 114, 88-105.

34 Kessick, M.A. and Denis, E.St (1982) Pipeline Transport of Heavy Crude Oil. US Patent 4343323.

35 Verzaro, F., Bourrel, M., Garnier, O., Zhou, H.G., and Argillier, J.F. (2002) Heavy Acidic Oil Transportation by Emulsion in Water. SPE 78959.

36 Wegener, D.C., Zornes, D.R., Maloney, D.R., Vienot, M.E. and Fraim, M.L (2001) Heavy Oil Viscosity Reduction and Production. US Patent 6279653. 
37 Sanchez, L.E. and Zakin, J.L. (1994) Transport of Viscous Crudes As Concentrated Oil-In-Water Emulsions. Industrial \& Engineering Chemistry Research, 33, 3256-3261.

38 Adewusi, V.A. and Ogunsola, A.O. (1993) Optimal Formulation of Caustic Systems for Emulsion Transportation and Dehydration of Heavy Oil. Chemical Engineering Research \& Design, 71, 62-68.

39 Zhang, J., Chen, D., Yan, D., and Yang, X. (1991) Pipelining of Heavy Crude Oil as Oil-in-Water Emulsions. SPE 21733.

40 Yaghi, B.M. and Al Bemani, A. (2002) Heavy Crude Oil Viscosity Reduction for Pipeline Transportation. Energy Sources, 24, 93-102.

41 Zaki, N.N., Butz, T. and Kessel, D. (2001) Rheology, Particle Size Distribution, and Asphaltene Deposition of Viscous Asphaltic Crude Oil-in-Water Emulsions for Pipeline Transportation. Petroleum Science and Technology, 19, 425435.

42 Zaki, N.N., Ahmed, N.S. and Nassar, A.M. (2000) Sodium Lignin Sulfonate to Stabilize Heavy Crude Oil-in-Water Emulsions for Pipeline Transportation. Petroleum Science and Technology, 18, 1175-1193.

43 Plegue, T.H., Zakin, J.L., Frank, S.G. and Fruman, D.H. (1985) Studies of Water Continuous Emulsions of Heavy Crude Oils. SPE 15792.

44 Layrisse, I.A., Polanco, D.R., Rivas, H., Jimenez, E., Quintero, L., Salazar, J., Rivero, M., Cardenas, A., Chirinos, M.L., Rojas, D. and Marquez, H. (1990) Viscous Hydrocarbon-in-Water Emulsions. US Patent 4923483.

45 Zaki, N.N. (1997) Surfactant Stabilized Crude Oil-in-Water Emulsions for Pipeline Transportation of Viscous Crude Oils.
Colloids and Surfaces A-Physicochemical and Engineering Aspects, 125, 19-25.

46 Nunez, G., Briceno, M., Mata, C., Rivas, H. and Joseph, D. (1996) Flow Characteristics of Concentrated Emulsions of Very Viscous Oil in Water. Journal of Rheology, 40, 405423.

47 Briant, J., Fruman, D.H., Quemada, D. and Makria, A. (1982) Transport de pétroles bruts lourds sous forme d'émulsion huile dans eau. Revue de l'Institut Français du Pétrole, 37, 809-821.

48 Fruman, D.H. and Briant, J. (1983) Investigation of the Rheological Characteristics of Heavy Crude Oil-in-Water Emulsions. International Conference on the Physical Modeling of Multi-Phase Flow, Coventry, England.

49 Simon, R. and Poynter, W.G. (1970) Pipelining Oil/Water Mixtures. US Patent 3519006.

50 Salager, J.L., Briceno, M.I. and Brancho, C.L. (2001) Heavy Hydrocarbon Emulsions, In Encyclopedic Handbook of Emulsion Technology, Sjöblom, J. (ed), Marcel Dekker, New York.

51 Ahmed, N.S., Nassar, A.M., Zaki, N.N. and Gharieb, H.K. (1999) Formation of Fluid Heavy Oil-in-Water Emulsions for Pipeline Transportation. Fuel, 78, 593-600.

52 Khan, M.R. (1996) Rheological Properties of Heavy Oils and Heavy Oil Emulsions. Energy Sources, 18, 385-391.

53 McKibben, M.J., Gillies, R.G., and Shook, C.A. (2000) A Laboratory Investigation of Horizontal Well Heavy OilWater Flows. Canadian Journal of Chemical Engineering, 78, 743-751.

Final manuscript received in September 2004 or distributed for profit or commercial advantage and that copies bear this notice and the full citation on the first page. Copyrights for components of this work owned by others than IFP must be honored. Abstracting with credit is permitted. To copy otherwise, to republish, to post on servers, or to redistribute to lists, requires prior specific permission and/or a fee. Request permission from Documentation, Institut français du pétrole, fax. +33147527078 , or revueogst@ifp.fr. 